\title{
"Shut it Down!": Teaching Heresthetic by Simulating the Budget Process
}

\author{
Alex P. Smith \\ University of Florida \\ alexpsmith@ufl.edu
}

\author{
Stephen C. Phillips \\ University of Florida \\ scphillips@ufl.edu
}

\begin{abstract}
William Riker argued political skills and strategies can be developed through two methods: instruction or practice. Simulations offer opportunities for students to receive instruction in political strategies and practice developing political skills without the real-world consequences faced by policymakers. Budget simulations introduce students to collective action problems prevalent at all levels of American government. While developing and passing a budget provides students with practice, carefully constructing the simulation introduces the heresthetic tactics of agenda setting, strategic voting, and dimension manipulation. By incorporating these strategies into the simulation, students must navigate conflicting interests - maximize personal gains and risk not adopting a budget, or cooperate and approve a budget that may not align with personal preferences. When used in American government and political institution courses, the budget simulation helps students identify choices policymakers encounter and develop the skills necessary for navigating those situations and the broader policymaking process.
\end{abstract}

Keywords: TLC2020, simulations and games, legislature, budget, collective action, heresthetic

\section{Introduction}


One challenge in teaching introductory political science courses is keeping students required to take the course to meet general education requirements engaged and interested. One pedagogical tool for facilitating student engagement and learning is in-class simulations. Political science courses can utilize simulations to promote student learning and engagement by mimicking a real political scenario, thereby permitting students to experience political processes in action. Simulations also provide students with the opportunity to learn about, and develop, strategies for political negotiation.

By simulating real-world political scenarios, students can be introduced to the types of strategic maneuvers political actors deploy in their efforts to achieve their desired outcomes. For example, simulating the budget process introduces students to collective action problems prevalent at the local, state, and federal levels of American politics. Simulations provide a context in which experimenting with strategies is safe and the consequences of failed strategies are relatively risk-free. This provides students "an opportunity to learn from firsthand experience in much the same way that laboratory experiments allow students of the physical sciences to observe actual physical processes" (Asal and Blake 2006, 2).

While developing and passing a budget alone provides students with significant practice, carefully constructing the parameters of the simulation introduces the heresthetic tactics of agenda setting, strategic voting, and dimension manipulation (Riker 1986). By incorporating these strategies into the simulation, students must navigate conflicting interests. Students can choose to maximize personal gains and risk not adopting a budget or cooperate with colleagues in approving a budget that may not align with their personal preferences.

Active learning strategies, such as simulations, are helpful pedagogical tools that enhance student learning. One reason simulations are effective in producing student learning is that they 
place students in situations they may encounter outside the confines of the classroom. The simulation helps students apply course materials to real life scenarios. The literature on simulations emphasizes that many students learn from simulations because they experience concepts in action (Alberda 2016, 872; Dorn 1989, 3; Pautz 2011, 648; Wedig 2010, 548). Simulations facilitate learning by "encourage[ing] students to do more than simply read about concepts and instead engage in actual experiences with them, increasing both students' motivation and interest" (Pautz 2011, 648). Simulations often require that students step into a role as an actor, which provides "the opportunity to internalize interests and motivations in a way that reading or lectures simply cannot duplicate" (Wedig 2010, 548).

The bases of intractable conflicts and unresolved issues become much clearer to students through the simulation experience, generating teachable moments for the instructor (Wedig 2010, 548). When students take their role in the simulation seriously, they enjoy the activity; moreover, they become more active and engaged in the course, which increases receptivity to learning. Bromley $(2013,819)$ finds that these are not only short-term benefits: "Simulations help students engage more deeply with course material, understand complexity, perform better on assignments, and better retain material over time." Not only have simulations of government processes demonstrated a measurable impact on student learning (Baranowski 2006, 41), the increased engagement and participation also has additional benefits for preparing students to be active, informed citizens.

In addition to learning course materials and concepts, simulations help students develop important skills for civic engagement. Simulations place students "in role-play situations where they need to make defensible decisions and often have to convince others to work with them," thereby providing "students with the opportunity to develop their communication, negotiation, 
and critical thinking skills, and in many cases, improve teamwork skills" (Asal and Blake 2006, 2). Bromley $(2013,818)$ also finds these scenarios can help students develop critical thinking skills, as well as their writing and communication abilities.

Simulations provide students with opportunities to encounter and overcome collective action problems through collaboration and teamwork (Pautz 2011, 648; Wedig 2010, 547). In simulations, students are typically confronted with collective and personal interests and develop strategies to navigate conflicting goals and desires. For that reason, it is helpful for the instructor to maximize student learning after the simulation is finished so that students can process and discuss the challenges that arose. Once students complete the simulation it is important for the instructor to help students "unpack the motivations and strategies of the participants... as part of the debriefing process, [as this] provides an opportunity for participants to reconsider their strategies and tactics and take lessons away from the exercise" (Wedig 2010, 548). The debriefing process "provides the analytical thinking needed to process the information that the students gained from the experience...bringing meaning to the experience and for learning from that meaning" (Dorn 1989, 11). It is in the debriefing process that specific political strategies, such as William Riker's (1986) concept of heresthetic, can be introduced to help students understand the motives behind strategies deployed in deliberative political bodies.

\section{Heresthetic and Budget Simulations}

Riker describes heresthetic as political strategies for decision-making predicated on the goal of "structuring the world so that you can win" (Riker 1986, ix). Though heresthetic is about achieving a desirable outcome, it is equally about avoiding an undesirable outcome; in other words, heresthetic is not always about winning, it is also about not losing. 
Riker (1986) identifies three different types of heresthetic tactics used by political actors: agenda setting, strategic voting, and dimension manipulation. The goal of agenda setting is to structure the order of alternatives in such a way that the agenda setter eliminates undesirable alternatives that, if discussed in a different order, would likely result in one of those outcomes winning (Riker 1986, 148). By structuring the order of debate, agenda setters are able to "defeat what is, on paper, the certain winner" (Riker 1986, 148). Political science literature on agenda setting is well-developed, yet the concepts of strategic voting and dimension manipulation have not been explored to the same extent. Riker describes strategic voting as "the flip side of agenda control" in that individuals "can sometimes win by appropriate use of their vote resource" (Riker $1986,149)$. Strategic voting is defined as "voting contrary to one's immediate tastes in order to obtain an advantage in the long run" (Riker 1986, 78). Strategic voting can entail vote trading between various factions. Dimension manipulation attempts to redefine the debate through "the invention of a new viewpoint, but it also requires rhetorical success in persuading indifferent people to accept the novelty" (Riker 1986, 34). Dimension manipulation succeeds because "once a salient dimension is revealed, its salience exists regardless of one's attitude toward it" (Riker 1986, 151). Together, the strategies of agenda setting, strategic voting, and dimension manipulation comprise a set of political tactics that can be used in any deliberative decisionmaking process consisting of multiple people.

Riker lamented that opportunities to develop skills in political strategy are very limited. He praised strategic politicians who are able to find ways to win, and claims these skills can be learned in two ways: practice or instruction (Riker 1986, ix). The best way to learn how to think strategically, he claimed, was through practice. Yet learning through practice is somewhat of a Catch-22: 
the novice heresthetician must learn by practice how to go about managing and manipulating and maneuvering to get the decisions he or she wants. Practice is, however, difficult to engage in, especially since one must win often enough to become a political leader before one has much opportunity to practice (Riker 1986, ix).

You must win elections to find yourself in an environment to develop strategic skills through practice, but if you fail in practice while developing those skills, you may be defeated in your bid for re-election or removed from appointed office due to those 'failures'.

It is possible to learn through instruction rather than practice, but strategic skills cannot be honed or tested through instruction alone. Additionally, instruction in heresthetics is "hard to come by, because the literature of heresthetic is fugitive, consisting mostly of occasional comments and stories in books about politics and politicians. Consequently, there is a real need for more copious illustrative instruction" (Riker 1986, ix). Though Riker seems to think practice can only exist in real political office, we believe the intentional use of in-class simulations provides an environment wherein both instruction and practice in the art of political strategy may occur. By combining heresthetic instruction with practice (in the form of classroom simulations), political science courses can efficiently and effectively introduce students to political strategy and provide an environment where students can test and hone those skills.

A simulation of the budget process was chosen because passing a budget is a core function of all governments. Budget simulations are also versatile in that they can be included in a variety of courses in American Politics (e.g., Intro to American Government, Congress, the Presidency, State and Local Government, etc.). Additionally, the simulation can be altered for each course to emphasize different elements of the process for particular institutions. For example, an Introduction to American Government course can provide a brief overview of the federal budget-making process, while a State and Local Government course can simulate the unique aspects of a particular state's budget process and interests. Through a simulation of the 
budget process, students are introduced to an important aspect of government that influences their lives, and it provides them with tools to engage in substantive debates when the federal, state, and/or local governments undertake this vital process.

\section{Simulation Design}

Over the past two years, we have constructed and employed a budgetary simulation in various forms across a number of introductory and upper division American government, public policy, and institution courses. During this time, the simulation has been refined in terms of both the instruction and practice discussed by Riker. In this section, we will review the most recent iteration of the simulation, while noting other variations we have utilized. In laying out the ground rules for our simulation, it is important to note the structure of our classes. Courses are typically offered in face-to-face format in 50-minute blocks that are held three times per week. The simulation is designed to last two class sessions, though it has also been completed in one 75-minute session.

We introduce the simulation to students midway through the semester after covering concepts and institutions comprising important knowledge for its execution. Specifically, following discussion of the collective action problem in legislative settings or bureaucratic agencies, and after units on the budgetary and fiscal processes themselves - relevant laws, procedures, and actors. This timeline provides students with background information on how the budgetary process unfolds in real life and allows the activity to be condensed into a shorter timeframe.

On the first day of the simulation, students are provided with an overview of the activity, including all instructions and preliminary information necessary for completion. Before beginning, students are randomly separated into groups representing the two chambers of a 
bicameral legislature - a structural feature of the federal government and all states except Nebraska. Not only are students randomly assigned to the House or Senate, they are designated a party affiliation (Democrat or Republican), and a position. Through this process the leaders of the respective chambers are selected, including a Speaker, Majority and Minority Leaders in the House, and a Senate President, Majority Leader, and Minority Leader. To reflect institutional structure and contemporaneous political dynamics, the group representing the lower house is twice as large as the upper house, with a Democratic majority in the House, and a Republican majority in the Senate.

After students are assigned roles, they separate into their groups. At this time, we provide additional information required for the simulation, including a written copy of the instructions to both leaders. The class is also shown the budget constructed by the professor that both chambers must modify, with a set dollar amount for the total budget, which neither house may alter. Simulation instructions specify that "it is up to each legislative chamber on how to organize itself" but that "bills [only] need a simple majority to pass." Students are instructed that each group, working independently, must allocate a specific dollar amount for each budget category provided, such as education, general government, health care, and transportation. At the outset, we provide the executive's budget proposal with rules requiring that it cannot be copied by either chamber. Students must therefore overcome the agenda setting power of the instructor in providing the budget and stipulating rules. Before they begin, students are informed that by the conclusion of the second day, there needs to be an enacted budget: the House and Senate have to pass the exact same budget, and the instructor - playing the role of executive — has to sign it into law. The class is incentivized to meet this objective either through their course participation grade or via the provision of a study guide for an upcoming exam, contingent on enactment of a 
budget, or extra credit points for the chamber whose budget from day one is most similar to the budget enacted on day two.

Simulation rules provide 30 minutes for each group to make changes to and pass a budget resolution. After this period, the class reviews the proposal passed by each chamber, with the instructor noting differences between the budgets. In our experience, the budgets passed by the different groups tend to be remarkably similar in most categories. To conclude day one of the simulation, students are instructed to form a conference committee to reconcile the differences between their budgets. The committee is comprised of an equal number of members from each group, and each chamber determines how to appoint members to the committee with the stipulation that party leaders are ineligible - forcing students to adapt to a new leadership dynamic.

At the beginning of the second day, students organize themselves into their respective chambers, and then members of the conference committee coalesce. Before the committee begins negotiations, we manipulate the dimensions of debate by introducing an intervening event. This can be any occurrence resulting in a redefinition of the decision-making environment, including natural disasters, wars, or an economic downturn. In this version of the simulation, students were informed that since the last class, the economy had entered a recession. Now, the conference committee had to reconcile differences between the chambers, and reduce the total dollar amount of the budget by $15 \%$. After introducing this twist to the simulation, the committee is given 20 minutes to debate and recommend a new budget proposal. During this time, members of the committee are permitted to consult with their chamber and leaders-though they seldom do.

Following this period, the class evaluates the committee's proposal. The instructor notes differences between the original chamber resolutions and the committee's budget proposal. Other 
than these brief reviews, the simulation requires little intervention on the part of the instructor, other than answering questions. After this review, committee members return to their chambers. Each group must then pass or reject the budget negotiated by the conference committee. While either or both chambers could reject the budget, or even make recommendations for changes, this has never occurred. Generally, students conclude the simulation before the end of the second day by briefly debating and then quickly accepting the proposal of the conference committee. The incentives offered to the students play an important role in this outcome by shaping their preferences in favor of enactment, due to the costs of failure to pass a budget.

Additional variations of the simulation have been successful. The simulation has been designed in different semesters to reflect the contours of the respective courses we have taught. This requires an emphasis on different aspect of the assignment. In one instance, three groups were assigned, representing a bicameral legislature and the Cabinet (including students selected as President, Vice President, and Cabinet secretaries). That iteration provides the student acting as president with veto power, requiring his or her colleagues to be cognizant of executive interests in formulating the budget. Other versions assigned additional positions, including committee chairs and further leadership positions (e.g., whips). One version of the simulation required a balanced budget: students were provided with a budget where spending exceeds projected revenue, and instructions required they could not adopt an unbalanced budget.

Instead of having students learn about institutional design, budgetary processes, and collective action from only textbook and lecture, students engage in a multi-day simulation within a group setting that can apply and exercise important political science concepts. Moreover, the bounds of the simulation provide a prime opportunity for students to practice elements of political strategy that are otherwise eschewed from the typical survey or upper 
division courses in our discipline; yet, these strategies provide an important introduction to how politics and political institutions function in real life.

\section{Debriefing Approaches}

Once the class has adopted a budget, we review and evaluate the exercise step-by-step with the students, while they remain in their groups. It is important to remind students that the simulation oversimplifies the budget-making process. We are careful to maintain key junctures, such as conflicting interests and veto points. We find that debriefing is a vital aspect of the simulation. Debriefing allows us to introduce and highlight specific instances from the simulation the class just completed to provide useful and digestible examples of political strategy for instruction — such as the instructors agenda setting power or how senators traded votes. Using cases for instruction based on the student's own actions prompts critical engagement on the student's part and allows for a reflection of their own role and actions during the simulation. This goes far beyond the passive engagement typical of lectures. Instead of learning political strategy from a textbook or slides, students reflect on their behavior in real time in collaboration with the very peers they completed the simulation with.

\section{Discussion}

In all iterations of the budget simulation we have conducted to this point, each class has enacted a budget before the deadline. The intervening events introduced on the second day have prompted students to re-consider their priorities and make adjustments to their budgets. Our most recent iteration, which required students to cut $15 \%$ of total dollars from the budget, resulted in conferees debating and deciding to not significantly cut budget categories — such as health care and welfare, and business and labor - that gain increased importance during a recession. Students even agreed to not cut transportation so people "could get to the jobs they still have." When 
conferees reduced the budget by too much, they reallocated money to business and labor to help fuel the economy. In completing the simulation, students also endeavor to represent their assigned positions, with one House Speaker remarking during an exchange with senators that "we're closer to the people," a representation of real-world institutional dynamics.

Incentives to complete the simulation encourages students to consider their short-term goals and long-term interests. In one version of the simulation, Senate members spent considerable time on the second day debating and approving changes to the conference report. Senators not only discussed specific items to amend, they exchanged support for specific changes - illustrative of vote-trading. Yet, once the chamber learned the committee's proposal was approved by the House, the Senate quickly followed. Senators preferred changes to the budget but deferred to receive the study guide, a textbook example of strategic voting.

When trying to evaluate the effectiveness of any pedagogical strategy, student feedback is vital. Students in our courses have indicated that the simulation was not only enjoyable, but that application and active engagement helped them understand and appreciate course concepts. As a result, students were more engaged in the course, if only temporarily. During end of the semester feedback, our students have requested additional in-class activities centered around application of materials. Students have also requested more time for the debriefing phase in order to better understand examples of agenda setting, strategic voting, and dimension manipulation. A majority of students in these courses have commented that the budget simulation was their favorite aspect of the respective course.

\section{Conclusion}

Budget simulations are an effective activity for applying course concepts to real world scenarios and providing students a brief introduction to political strategy. In creating and passing 
a budget, students are introduced to the types of challenges elected officials face in performing their legislative duties, and the tactics used to not only fulfill those duties, but to reach a desirable outcome. Simulating the budget process is effective because students recognize this responsibility as a core duty of all levels of government. Budget simulations, therefore, can be utilized in multiple American Politics courses and altered to emphasize elements of the budget specific to the level of government or primary institution being studied. The versatility of the budgetary process makes this simulation ideal for instructors and students alike. Instruction in heresthetic through the debriefing process introduces students to specific examples of political strategy — agenda setting, strategic voting, and dimension manipulation-helping students to make sense of the dilemmas and decisions present in the simulation. Providing this type of instruction and practice can help students experience political processes and strategies firsthand. Creating such 'laboratories' for students to discover, develop, and hone their political skills may produce an effective set of future leaders. 


\section{References}

Alberda, Gayle. 2016. "Campaign Simulation for American Government: An Active Learning Approach to Campaigns and Elections." PS: Political Science \& Politics 49(4): 872-75.

Asal, Victor, and Elizabeth L. Blake. 2006. "Creating Simulations for Political Science Education." Journal of Political Science Education 2(1): 1-18.

Baranowski, Michael. 2006. "Single Session Simulations: The Effectiveness of Short Congressional Simulations in Introductory American Government Classes." Journal of Political Science Education 2(1): 33-49.

Bromley, Pam. 2013. "Active Learning Strategies for Diverse Learning Styles: Simulations are Only One Method.” PS: Political Science \& Politics 46(4): 818-22.

Dorn, Dean S. 1989. "Simulation Games: One More Tool on the Pedagogical Shelf." Teaching Sociology 17(1): 1-18.

Pautz, Michelle C. 2011. "Challenging the Constitution: Convening a Mock Constitutional Convention for American Government Students." PS: Political Science \& Politics 44(3): $648-51$.

Riker, William H. 1986. The Art of Political Manipulation. New Haven, CT: Yale University Press.

Wedig, Timothy. 2010. "Getting the Most from Classroom Simulations: Strategies for Maximizing Learning Outcomes." PS: Political Science \& Politics 43(3): 547-55. 